\title{
A multi-production inventory model for deteriorating items considering penalty and environmental pollution cost with failure rework
}

\author{
T. Sekar ${ }^{\mathrm{a} *}$ and R. Uthayakumar
}

${ }^{a}$ Department of Mathematics, The Gandhigram Rural Institute - Deemed University, Gandhigram - 624 302, Dindigul, Tamil Nadu, India

\begin{tabular}{l}
\hline C H R O N I C L E \\
\hline Article history: \\
Received July 2, 2016 \\
Received in revised format \\
September 10, 2016 \\
Accepted December 222016 \\
Available online \\
December 232016 \\
\hline Keywords: \\
Multi-production run \\
Internally deteriorating items \\
Failure rework \\
Environmental pollution cost \\
Penalty cost \\
Scrap cost
\end{tabular}

\section{Introduction}

Nowadays, the facts like deterioration, shortages and remanufacturing of imperfect items are the frequently used terms in the global market. Another major issue, in the worldwide market, is how to reduce environmental pollution. Rework is one of the major issues in reverse logistic and green supply chain because it can decrease production cost and environmental problem. Many researchers focused on developing EPQ model for deteriorating items but few of them developed model for remanufacturing of imperfect items. In this paper, we develop an EPQ model for multi- production runs considering penalty cost for selling the deteriorating items to the customers and remanufacturing of imperfect items to reduce environmental pollution. In reality, production processes are often imperfect so that the imperfect items are generated. For economic and ecological reasons, imperfect quality items are remanufactured to become serviceable items again. Due to inappropriate inventory condition or other causes, the remaining good quality items, stored in an inventory, are deteriorating. In order to provide good service to

\footnotetext{
* Corresponding author Tel.: +91-04257-241545, Fax: 91-04257-242007

E-mail address: sekarmat@yahoo.com (T. Sekar)

(C) 2017 Growing Science Ltd. All rights reserved. doi: 10.5267/j.uscm.2016.12.003
} 
customers, inspection is carried out to screen out imperfect and deteriorating items. However, such inspection may not be perfect (Zhou et al., 2015) and only part of imperfect items manufactured are not fruitfully screened out internally during the production process and passed on to customers, consequently causing defect sales returns and reverse logistics from customers back to the producer. One common source of inspection error is from human factors (Drury, 1978; Drury \& Prabhu, 1994). The principal operation strategies and goals of most manufacturing firms have to seek a high satisfaction to customer's demands and also to become a low-cost producer. To reach these goals, the company should be able to effectively utilize the resources and minimize the costs. Rework is very common in semiconductor, pharmaceutical, chemical and food industries. The products are considered as deteriorating items since their utility is lost with storage time due to price reduction, product useful life expiration, decay and spoilage. In our lot sizing model for deteriorated items with rework, both perfect and imperfect items are deteriorating with time.

The remainder of this paper is organized as follows. In section 2, we give a literature review. In section 3 , assumptions and notations are given. The mathematical formulation for this model is given in section 4. Solution method of this model is given in section 5. Numerical example and sensitivity analysis are given in section 6 , and conclusion is drawn in section 7 .

\section{Literature Review}

Economic Production Quantity (EPQ) model is a prominent research topic in manufacturing, inventory control and management. By using EPQ model, optimal quantity of items and optimal production run time can be obtained. Classical EPQ model was developed under various assumptions. Thereafter, researchers have extended the model by relaxing one or more of the assumptions. It was assumed that the items produced are of perfect quality items in the classical EPQ model. However, in reality, imperfect quality items may be produced. Kumar et al. (2011) presented Economic Production Lot Size (EPLS) model with stochastic demand and shortage with partial backlogging rate under imperfect quality items, in which stochastic imperfect production was assumed. Yassine et al. (2012) considered disaggregating the shipments of imperfect quality items in single production run and aggregating the shipments of imperfect items over multi production runs. Pal et al. (2014) scheduled an EPQ inventory model for ramp type demand with Weibull deterioration under inflation in finite time horizon in crisp and fuzzy environment. It was further extended by Pal et al. (2015) allowing shortages. Mukhopadhyay et al. (2015) investigated an economic production quantity model for three types of imperfect items with rework. Singh et al. (2015) presented a mathematical production inventory model for deteriorating items with time dependent demand rate including the effect of inflation and shortages. Shukla et al. (2016) presented an economic production quantity model with defective products for deteriorating products. Jaggi et al. (2016b) investigated an inventory model for non-instantaneous deteriorating items under inflationary conditions with partially backlogged shortages.

Rezaei et al. (2012) discussed an economic production quantity and purchasing price for items with imperfect quality when inspection shifts from buyer to supplier. Mishra et al. (2013) considered an inventory model for deteriorating items with time-dependent demand and time dependent holding cost under partial backlogging. Barketau et al. (2015) presented a modified EPQ model with deteriorating production system and deteriorating product where rework process was considered at the end of production setup. Chandra et al. (2015) introduced the effect of deterioration on two-warehouse inventory model with imperfect quality items. Kumar et al. (2016) have developed a general inventory model for deteriorating items with probabilistic deterioration rate and ramp type demand under stock dependent consumption rate. Jaggi et al. (2016a) studied an inventory model for a retailer dealing by deteriorating items under inflationary conditions over a fixed planning horizon. A two-warehouse inventory model for deteriorating items with price dependent demand under partial backlogging was discussed by Rastogi et al. (2017).

Remanufacturing process is also an important issue in reverse logistics where used products are remanufactured to reduce total inventory cost, waste and ecological problem. The earliest research that 
focused on remanufacturing process was done by Schrady (1967). Since then, researches on rework have attracted many researchers. Khouja (2000) planed direct rework for Economic lot Sizing and Delivery Scheduling Problem (ELDSP). Yoo et al. (2009) presented an EPQ model with imperfect production, imperfect inspection and rework. Widyadana et al. (2012) developed an EPQ model for deteriorating items with rework wherein the rework was performed after $m$ production setups. Tai (2013) proposed an EPQ model for deteriorating/imperfect products with rework wherein the rework was performed at the end of production setup. Sarkar et al. (2014) assumed rework for single stage production system. Hsu et al. (2014) considered an EPQ model under an imperfect production process with shortages backordered. An EPQ model based on the retailer's stock level was proposed by Kaliraman et al. (2015) wherein it is prescribed that the rate of deterioration is Weibull distribution and the production cost is consisting of raw material cost, labor cost, wear and tear cost and environmental cost. Singh et al. (2014) proposed an economic production model for time dependent demand with rework and multiple production setups where production is depending on the demand. Due to learning effect of employees, holding cost partially constant and partially decreasing in each cycle which is studied in Sangal et al. (2016). Khanna (2017) formulated a strategic production model to study the combined effects of imperfect quality items, inspection error and remanufacturing process under two level trade credits. We notice that not many studies considered a model with multimanufacturing setups including defective items considering penalty cost, scrap cost and rework. In this paper, we intend at providing analytic results to solve the said above issues.

\section{Assumptions and Notations}

The inventory model is developed with the following assumptions and notations:

\section{1. Assumptions}

1. Production and demand rate are constants.

2. Rework and deterioration rate are constants.

3. Deterioration starts as soon as it comes to the inventory.

4. There is a replacement for deteriorated items.

5. This model is considered under finite time horizon.

6. The lead time is assumed as negligible.

7. The production rate of serviceable items and rework must be greater than the demand rate.

8. No machine breakdown occurs during production run and rework process.

9. The inspection cost is incorporated in the unit production cost.

10. Shortages are not permitted.

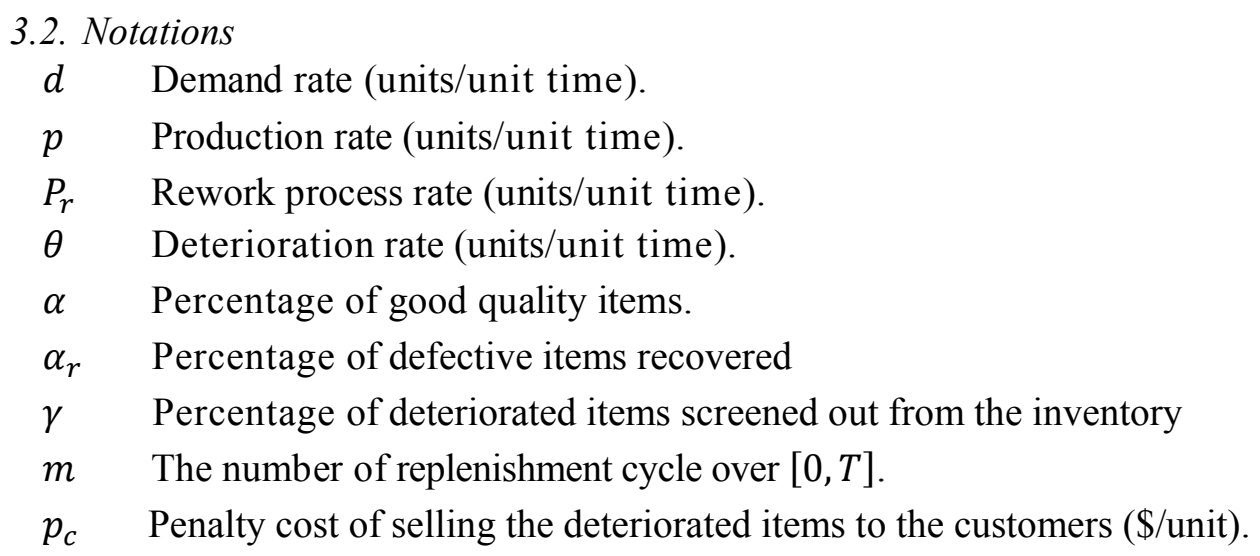




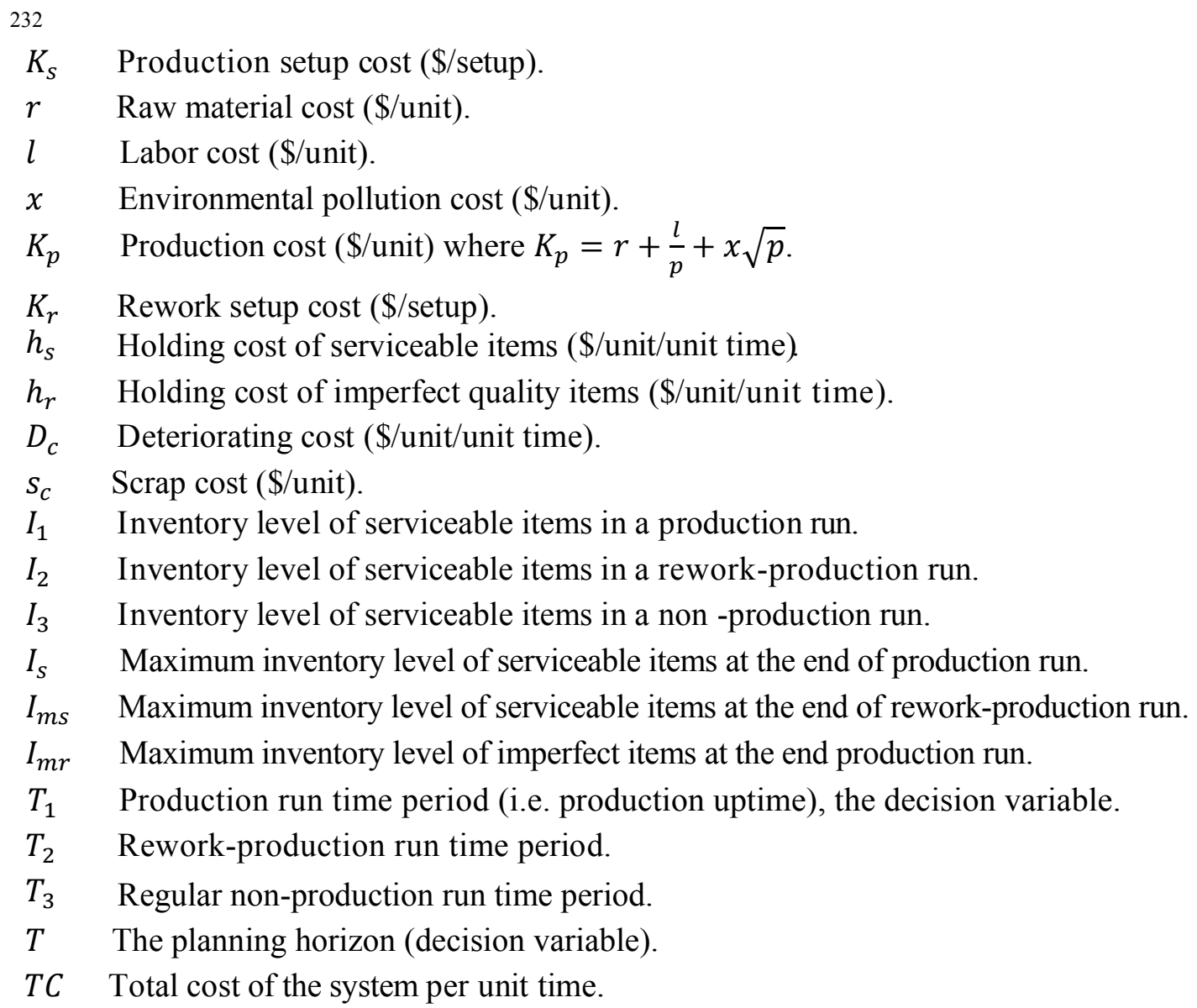

\section{Formulation of the model}

The behavior of the inventory level of serviceable items with $m$ production runs is studied as illustrated in Fig. 1. The production run is performed during $T_{1}$ time period. When production run is established, $(1-\alpha) p$ defect products are produced per unit time. $T_{2}$ is the rework production run time period. $T_{3}$ is non-production run time period.

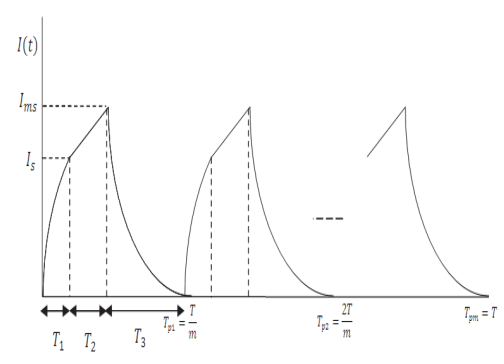

Fig. 1. Graphical representation of the EPQ inventory system

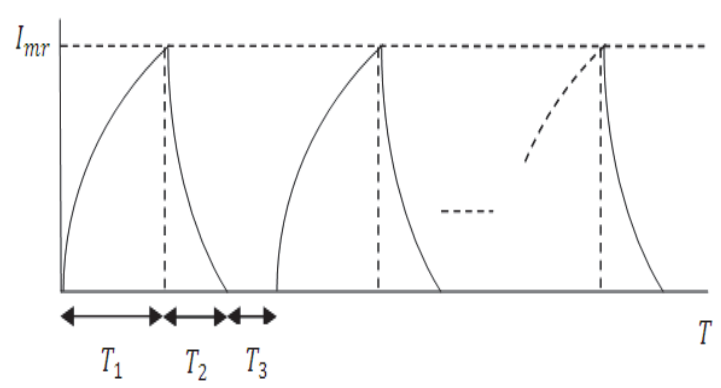

Fig. 2. Graphical representation of the reworkproduction runs

The inventory level of serviceable items in a production period can be formulated as:

$\frac{d I_{1}\left(t_{1}\right)}{d t_{1}}+\gamma \theta I_{1}\left(t_{1}\right)=\alpha p-d \quad 0 \leq t_{1} \leq T_{1}$

Since $I_{1}(0)=0$, the inventory level of serviceable items in a production period is:

$\mathrm{I}_{1}\left(\mathrm{t}_{1}\right)=\frac{\alpha p-d}{\gamma \theta}\left[1-e^{-\gamma \theta t_{1}}\right] \quad 0 \leq t_{1} \leq T_{1}$ 
The inventory level of serviceable items in a rework process is represented as:

$\frac{d I_{2}\left(t_{2}\right)}{d t_{2}}+\gamma \theta I_{2}\left(t_{2)}=\left(\alpha_{r} p_{r}-d\right) \quad 0 \leq t_{2} \leq T_{2}\right.$

Since $I_{2}(0)=I_{S}$, the inventory level of serviceable items in a production run time period is:

$$
I_{2}\left(t_{2}\right)=\left(I_{s}-\frac{\left(\alpha_{r} p_{r}-d\right)}{\gamma \theta}\right) e^{-\gamma \theta t_{2}}+\frac{\left(\alpha_{r} p_{r}-d\right)}{\gamma \theta} \quad 0 \leq t_{2} \leq T_{2}
$$

The inventory level of serviceable item in a non-production period is represented as:

$$
\frac{d I_{3}\left(t_{3}\right)}{d t_{3}}+\gamma \theta I_{3}\left(t_{3)}=-d \quad 0 \leq t_{2} \leq T_{2}\right.
$$

Since $I_{3}\left(T_{3}\right)=0$, the inventory level of serviceable item in a non-production run time period is:

$$
I_{3}\left(t_{3}\right)=\frac{d}{\gamma \theta}\left[e^{\gamma \theta\left(T_{3}-t_{3}\right)}-1\right]
$$

It can be deduced from Eq. (2) that the inventory level of serviceable items when $t_{1}=T_{1}$ is:

$$
I_{s}=\frac{\alpha p-d}{\gamma \theta}\left[1-e^{-\gamma \theta T_{1}}\right]
$$

The maximum inventory level of serviceable items, when $t_{2}=T_{2}$, from Eq. (4), is

$$
I_{m s}=I_{s} e^{-\gamma \theta T_{2}}+\frac{\left(1-e^{-\gamma \theta T_{2}}\right)\left(\alpha_{r} p_{r}-d\right)}{\gamma \theta}
$$

The maximum inventory level of imperfect quality items in a production run is given by

$$
I_{m r}=(1-\alpha) p T_{1}=p_{r} T_{2} \quad \text { (See Fig. 2) }
$$

Using Eq. (9), we can derive the rework-production run time in terms of $T_{1}$ :

$$
T_{2}=\frac{(1-\alpha) p}{p_{r}} T_{1}
$$

The relation between $T_{i}(i=1,2,3)$ and $T$ is $T=T_{1}+T_{2}+T_{3}$. From the relation we can easily find out the non-production run time period $\left(T_{3}\right)$ in terms of $T_{1}$ which is given by:

$$
T_{3}=\frac{p_{r} T-\left(p_{r}+(1-\alpha) p\right)}{p_{r}} T_{1}
$$

The total cost function for $m$ replenishment cycle consists of the deteriorating cost, penalty cost of selling deteriorated items to customers, holding costs of serviceable and imperfect quality items, setup cost, production cost, rework cost and scrap cost. Our objective is to minimize the total cost function per unit time which can be stated as:

$$
T C=\left[\begin{array}{c}
\frac{D c}{T / m}\left\{m(\alpha p-d) T_{1}-m I_{s}\right\}+\frac{D c}{T / m}\left\{m\left(\alpha_{r} p_{r}-d\right) T_{2}-m\left(I_{m s}-I_{s}\right)\right\}+\frac{D c}{T / m}\left\{m\left(I_{m s}-d T_{3}\right)\right\} \\
+\frac{(1-\gamma)}{\gamma}\left\{\frac{p_{c}}{T / m}\left[m(\alpha p-d) T_{1}-m I_{s}\right]+\frac{p_{c}}{T / m}\left[m\left(\alpha_{r} p_{r}-d\right) T_{2}-m\left(I_{m s}-I_{s}\right)\right]+\frac{p_{c}}{T / m}\left[m\left(I_{m s}-d T_{3}\right)\right]\right\} \\
+\frac{h_{s}}{T / m}\left\{m \int_{0}^{T_{1}} \mathrm{I}_{1}\left(\mathrm{t}_{1}\right) d t_{1}+m \int_{0}^{T_{2}} \mathrm{I}_{2}\left(\mathrm{t}_{2}\right) d t_{2}+m \int_{0}^{T_{3}} \mathrm{I}_{3}\left(\mathrm{t}_{3}\right) d t_{3}\right\}+\frac{h_{r}}{T / m}\left\{\frac{m\left(T_{1}+T_{2}\right) p_{r} T_{2}}{2}\right\}+\frac{m k_{s}}{T / m} \\
+\frac{m k_{p}}{T / m} p T_{1}+\frac{m p_{r} T_{2}}{T / m} k_{r}+\frac{m s_{c}}{T / m}\left(1-\alpha_{r}\right) p_{r} T_{2}
\end{array}\right]
$$

Simplifying the first and second term of TC in Eq. (12), it reduces to 


$$
\left(\frac{m^{2} D_{c} \gamma+m^{2}(1-\gamma) p_{c}}{\gamma}\right)\left((\alpha p-d) T_{1}+\left(\alpha_{r} p_{r}-d\right) T_{2}-d T_{3}\right)
$$

Using Eq. (10) and (11) in Eq. (13) which results

$$
\frac{\mu(\alpha p-d) T_{1}}{T}+\frac{\mu\left(\alpha_{r} p_{r}-d\right)(1-\alpha) p T_{1}}{T p_{r}}+\frac{\mu d\left(p_{r}+(1-\alpha) p\right) T_{1}}{T p_{r}}-\frac{\mu d}{m}
$$

where $\mu=\frac{m^{2} D_{c} \gamma+m^{2}(1-\gamma) p_{c}}{\gamma}$

With Eq. (14), the first and second term of $T C$ in Eq. (12) then becomes

$$
T C=\left[\begin{array}{c}
\frac{\mu(\alpha p-d) T_{1}}{T}+\frac{\mu\left(\alpha_{r} p_{r}-d\right)(1-\alpha) p T_{1}}{T p_{r}}+\frac{\mu d\left(p_{r}+(1-\alpha) p\right) T_{1}}{T p_{r}}-\frac{\mu d}{m} \\
+\frac{h_{s}}{T / m}\left\{m \int_{0}^{T_{1}} \mathrm{I}_{1}\left(\mathrm{t}_{1}\right) d t_{1}+m \int_{0}^{T_{2}} \mathrm{I}_{2}\left(\mathrm{t}_{2}\right) d t_{2}+m \int_{0}^{T_{3}} \mathrm{I}_{3}\left(\mathrm{t}_{3}\right) d t_{3}\right\}+\frac{h_{r}}{T / m}\left\{\frac{m\left(T_{1}+T_{2}\right) p_{r} T_{2}}{2}\right\} \\
+\frac{m k_{s}}{T / m}+\frac{m k_{p}}{T / m} p T_{1}+\frac{m p_{r} T_{2}}{T / m} k_{r}+\frac{m s_{c}}{T / m}\left(1-\alpha_{r}\right) p_{r} T_{2}
\end{array}\right]
$$

It can be shown that the second term of TC in Eq. (15) as

$\frac{m^{2} h_{s}}{T}\left\{\frac{(\alpha p-d)}{2} T_{1}^{2}+(\alpha p-d) T_{1} T_{2}+\frac{\left(\alpha_{r} p_{r}-d\right)}{2} T_{2}^{2}+\frac{d}{2} T_{3}^{2}\right\}+\frac{h_{r}}{T}\left\{\frac{m^{2}\left(T_{1}+T_{2}\right) p_{r} T_{2}}{2}\right\}$

The derivation of the above term can be found in the Appendix.

Using Eq. (10) and Eq. (11) in the above equation which gives:

$$
\left[\begin{array}{c}
\frac{m^{2} h_{s}(\alpha p-d) T_{1}^{2}}{2 T}+\frac{m^{2} h_{s}(\alpha p-d)(1-\alpha) p T_{1}^{2}}{T p_{r}}+\frac{m^{2} h_{s}\left(\alpha_{r} p_{r}-d\right)(1-\alpha)^{2} p^{2} T_{1}^{2}}{2 T p_{r}^{2}}+\frac{h_{s} d T}{2} \\
+\frac{m^{2} h_{s} d\left(p_{r}+(1-\alpha) p\right)^{2} T_{1}^{2}}{2 T p_{r}^{2}}-\frac{m h_{s} d\left(p_{r}+(1-\alpha) p\right) T_{1}}{p_{r}}+\frac{m^{2} h_{r}(1-\alpha) p T_{1}^{2}}{2 T}+\frac{m^{2} h_{r}(1-\alpha)^{2} p^{2} T_{1}^{2}}{2 T p_{r}}
\end{array}\right]
$$

Finally, we can express $T C\left(T_{1}, T\right)$ in Eq. (15) in terms of $T$ and $T_{1}$ only:

$$
T C\left(T_{1}, T\right)=\left[\begin{array}{c}
\frac{\mu(\alpha p-d) T_{1}}{T}+\frac{\mu\left(\alpha_{r} p_{r}-d\right)(1-\alpha) p T_{1}}{T p_{r}}+\frac{\mu d\left(p_{r}+(1-\alpha) p\right) T_{1}}{T p_{r}}-\frac{\mu d}{m} \\
\frac{m^{2} h_{s}(\alpha p-d) T_{1}^{2}}{2 T}+\frac{m^{2} h_{s}(\alpha p-d)(1-\alpha) p T_{1}^{2}}{T p_{r}}+\frac{m^{2} h_{s}\left(\alpha_{r} p_{r}-d\right)(1-\alpha)^{2} p^{2} T_{1}^{2}}{2 T p_{r}^{2}}+\frac{h_{s} d T}{2} \\
+\frac{m^{2} h_{s} d\left(p_{r}+(1-\alpha) p\right)^{2} T_{1}^{2}}{2 T p_{r}^{2}}+\frac{m h_{s} d\left(p_{r}+(\alpha-1) p\right) T_{1}}{p_{r}}+\frac{m^{2} h_{r}(1-\alpha) p T_{1}^{2}}{2 T}+\frac{m^{2} h_{r}(1-\alpha)^{2} p^{2} T_{1}^{2}}{2 T p_{r}} \\
\frac{m^{2} k_{s}}{T}+\frac{p m^{2} k_{p} T_{1}}{T}+\frac{m^{2} k_{r}(1-\alpha) p T_{1}}{T}+\frac{m^{2} s_{c}(1-\alpha)\left(1-\alpha_{r}\right) p T_{1}}{T}
\end{array}\right]
$$

To make our solution procedure trouble-free, we write the above Eq. (17) as:

$$
T C\left(T_{1}, T\right)=A T+B T_{1}+\frac{C}{T}+D \frac{T_{1}}{T}+E \frac{T_{1}^{2}}{T}+F .
$$

where $A=\frac{h_{s} d}{2}>0$,

$$
\begin{aligned}
& B=\frac{m h_{s} d\left(p_{r}+(\alpha-1) p\right)}{p_{r}}<0, \\
& C=m^{2} k_{s}>0
\end{aligned}
$$




$$
\begin{aligned}
& D=\left[\begin{array}{c}
\mu(\alpha p-d)+\frac{\mu\left(\alpha_{r} p_{r}-d\right)(1-\alpha) p}{p_{r}}+\frac{\mu d\left(p_{r}+(1-\alpha) p\right)}{p_{r}}+p m^{2} k_{p} \\
+m^{2} k_{r}(1-\alpha) p+m^{2} s_{c}(1-\alpha)\left(1-\alpha_{r}\right) p
\end{array}\right]>0 \\
& E=\left[\begin{array}{c}
\frac{m^{2} h_{S}(\alpha p-d)}{2}+\frac{m^{2} h_{S}(\alpha p-d)(1-\alpha) p}{p_{r}}+\frac{m^{2} h_{S}\left(\alpha_{r} p_{r}-d\right)(1-\alpha)^{2} p^{2}}{2 p_{r}^{2}} \\
+\frac{m^{2} h_{s} d\left(p_{r}+(1-\alpha) p\right)^{2}}{2 p_{r}^{2}}+\frac{m^{2} h_{r}(1-\alpha) p}{2}+\frac{m^{2} h_{r}(1-\alpha)^{2} p^{2}}{2 p_{r}}
\end{array}\right]>0 \text { and } \\
& F=-\frac{\mu d}{T}<0
\end{aligned}
$$

\section{Solution method}

In order to obtain the optimal solution of the model, a proof of the convexity of the objective function $T C\left(T_{1}, T\right)$ is provided. An optimization technique using partial derivatives is carried out to derive the optimal solutions.

Theorem 1. The objective function $T C\left(T_{1}, T\right)$ in (17) is strictly convex.

Proof: (See Appendix)

The optimal pair exists if $4 C E>D^{2}, 4 A E>D^{2}, B<0$ and $B \sqrt{4 C E-D^{2}}>D \sqrt{4 A E-D^{2}}$ and is given by

$$
\left(T_{1}^{*}, T^{*}\right)=\left(\frac{-1}{2 E}\left(B \sqrt{\frac{4 C E-D^{2}}{4 A E-B^{2}}}+D\right), \sqrt{\frac{4 C E-D^{2}}{4 A E-B^{2}}}\right)
$$

\section{Algorithm}

Step 1: Start.

Step 2: From the Eq. (18), find the values of A, B, C, D, E and F by initialising the values of the parameters $p, \alpha, \theta, d, r, x, k_{r}, s_{c}, \alpha_{r}, k_{s}, D_{c}, \gamma, p_{c}, h_{s}, h_{r}, l$ and $p_{r}$.

Step 3: From step 2, choose one set of values of A, B, C, D and E satifying the condition: $4 C E>D^{2}, 4 A E>D^{2}, B<0$ and $B \sqrt{4 C E-D^{2}}>D \sqrt{4 A E-D^{2}}$.

Step 4: Substitute the values of A, B, C, D and E, obtained in step 3, in Eq. (19) and calculate $T_{1}$ and $T$.

Step 5: Substitute the values of A, B, C, D, E, F, $T_{1}$ and $T$, obtained in step 2 and 4, in equation (18) and calculate the total inventory cost $(T C)$.

Step 6: If the values of C, D and E, obtained in step 2, satisfy the conditions $\frac{2 E}{T}>0$ and $\frac{1}{T^{4}}\left(2 E C-2 D E T_{1}-2 E^{2} T_{1}^{2}-D^{2}\right)>0$, then the corresponding values of $T_{1}, T$ and $T C$ obtained in step 4 and 5 , are taken as the optimal production run time (denoted by $T_{1}^{*}$ ), optimal finite planing horizon time (denoted by $T^{*}$ ) and minimum total inventory cost (denoted by $T C^{*}$ ) respectively. Otherwise go to setp 2 and choose another set of values of A, B, C, D and E.

Step 6: Repeat the steps 2 to 6 until we get $T_{1}^{*}, T^{*}$, and $T C^{*}$.

Step 7: End.

\section{Numerical example and sensitivity analysis}

In this section, a numerical example and sensitivity analysis are given to illustrate the model. 


\subsection{Numerical example}

Consider an inventory model with the following data $p=4000, \alpha=0.8, \theta=0.1, d=1545, r=$ $\$ 0.001, x=\$ 0.00035, k_{r}=\$ 0.5, s_{c}=\$ 2, \alpha_{r}=0.9, k_{s}=\$ 150, D_{c}=\$ 10, \gamma=0.7, p_{c}=$ $\$ 3, h_{s}=\$ 100, h_{r}=\$ 2, l=\$ 100$ and $p_{r}=2000$.

We follow from Eq. (18) that the optimal pair is given by

$\left(T_{1}^{*}, T^{*}\right)=(0.0209,0.3107)$

From Eq. (10) and (11) we can obtain rework process time and non-production time which is given by

$T_{2}^{*}=0.0083$.

$T_{3}^{*}=0.0329$.

From Eq. (7), the maximum inventory level of serviceable items during production run period:

$I_{s} \approx 35$ units

From Eq. (8), we get the maximum inventory level of serviceable items:

$I_{m s} \approx 51$ units

From Eq. (9), we get the maximum inventory level of recoverable items during production run period:

$I_{m r} \approx 17$ units.

The economic production quantities per production run:

$Q^{*}=p T_{1}^{*} \approx 83$ units.

The optimal total inventory cost per unit time is found to be

$T C^{*}=\$ 25394.76$

\subsection{Sensitivity analyzes}

In this section, we discuss the sensitivity analysis with the variation of different parameters. We now study about the effects of changes in the values of the parameters $\mathrm{k}_{\mathrm{r}}, \mathrm{s}_{\mathrm{c}}, \mathrm{h}_{\mathrm{s}}$ and $\mathrm{k}_{\mathrm{s} \text {. on the optimal }}$ production time, rework process time, non-production time, total inventory cost and economic production quantity based on our numerical results. We change one parameter at a time keeping the other parameters unchanged. The results of sensitivity analysis are summarized in Table 1 to 4 . The following managerial phenomena can be made from the results obtained.

(i) When rework setup cost $\mathrm{k}_{\mathrm{r}}$ increases/decreases, the optimal run time values of $\mathrm{T}_{1}, \mathrm{~T}_{2}$ and $\mathrm{T}$ decreases/increases, the optimal time value of $\mathrm{T}_{3}$ increases/decreases. The economic order quantity is reduced when the parameter $\mathrm{k}_{\mathrm{r}}$ increases. The total inventory cost of the manufacturer is increased when the parameter $\mathrm{k}_{\mathrm{r}}$ is increased. It is observed that as the length of the cycle time decreases (as the cycle time is reduced) the order quantity is also decreased with respect to the setup cost.

(ii) If the scrap cost is increased, then the optimal run time values of $T_{1}, T_{2}$ and $T$ are moderately sensitive but order quantity is decreased while total inventory cost per unit time of the manufacturer is increased. It is obvious that total average cost increases when setup cost increases. 
(iii) The holding cost of serviceable items is highly sensitive to the production run time, rework process time and cycle length. When the parameter $h_{s}$ decreases, $T_{1}, T_{2}, T_{3}, T$ and optimum quantity $\mathrm{Q}$ increases while the total inventory cost is decreased. It is obvious that total cost per unit time is decreased/increased when holding cost of the serviceable items is decreased/ increased.

(iv) When the setup cost is increasing/decreasing, the production run time, rework production run time, non-production time, replenishment cycle length, economic order quantity and total inventory cost are increasing/decreasing.

Table 1

Sensitivity analysis of rework setup cost $\mathrm{k}_{\mathrm{r}}$ on optimal values of $\mathrm{T}_{1}, \mathrm{~T}_{2}, \mathrm{~T}_{3}, \mathrm{~T}, \mathrm{Q}$ and TC

\begin{tabular}{lllllll}
\hline $\mathrm{k}_{\mathrm{r}}$ & $\mathrm{T}_{1}$ & $\mathrm{~T}_{2}$ & $\mathrm{~T}_{3}$ & $\mathrm{~T}$ & $\mathrm{Q}$ & $\mathrm{TC}$ \\
\hline 0.5 & 0.02087 & 0.00835 & 0.03293 & 0.31072 & 83 & 25394.76 \\
1 & 0.02016 & 0.00806 & 0.03379 & 0.31005 & 81 & 26055.67 \\
1.5 & 0.01943 & 0.00777 & 0.03461 & 0.30910 & 78 & 26695.16 \\
2 & 0.01869 & 0.00748 & 0.03541 & 0.30788 & 75 & 27313.03 \\
2.5 & 0.01792 & 0.00717 & 0.03618 & 0.30637 & 72 & 27909.02 \\
3 & 0.01713 & 0.00685 & 0.03693 & 0.30458 & 69 & 28482.82 \\
\hline
\end{tabular}

Table 2

Sensitivity analysis of scrap cost $\mathrm{S}_{\mathrm{c}}$ on optimal values of $\mathrm{T}_{1}, \mathrm{~T}_{2}, \mathrm{~T}_{3}, \mathrm{~T}, \mathrm{Q}$ and $\mathrm{TC}$

\begin{tabular}{lllllll}
\hline $\mathrm{S}_{\mathrm{c}}$ & $\mathrm{T}_{1}$ & $\mathrm{~T}_{2}$ & $\mathrm{~T}_{3}$ & $\mathrm{~T}$ & $\mathrm{Q}$ & $\mathrm{TC}$ \\
\hline 2 & 0.02087 & 0.00835 & 0.03293 & 0.31072 & 83 & 25394.76 \\
4 & 0.02073 & 0.00829 & 0.03310 & 0.31060 & 83 & 25528.65 \\
6 & 0.02030 & 0.00812 & 0.03362 & 0.31020 & 81 & 25925.19 \\
8 & 0.02002 & 0.00801 & 0.03395 & 0.30988 & 80 & 26185.29 \\
10 & 0.01973 & 0.00789 & 0.03429 & 0.30951 & 79 & 26441.94 \\
12 & 0.01943 & 0.00777 & 0.03461 & 0.30910 & 78 & 26695.16 \\
\hline
\end{tabular}

Table 3

Sensitivity analysis of holding cost $h_{\mathrm{s}}$ on optimal values of $\mathrm{T}_{1}, \mathrm{~T}_{2}, \mathrm{~T}_{3}, \mathrm{~T}, \mathrm{Q}$ and TC.

\begin{tabular}{ccccccc}
\hline $\mathrm{h}_{\mathrm{s}}$ & $\mathrm{T}_{1}$ & $\mathrm{~T}_{2}$ & $\mathrm{~T}_{3}$ & $\mathrm{~T}$ & $\mathrm{Q}$ & $\mathrm{TC}$ \\
\hline 100 & 0.02087 & 0.00835 & 0.03293 & 0.31072 & 83 & 25394.76 \\
90 & 0.02190 & 0.00876 & 0.03481 & 0.32740 & 88 & 24160.08 \\
80 & 0.02312 & 0.00925 & 0.03705 & 0.34709 & 92 & 22854.61 \\
70 & 0.02456 & 0.00983 & 0.03977 & 0.37082 & 98 & 21464.52 \\
60 & 0.02633 & 0.01053 & 0.04318 & 0.40021 & 105 & 19970.87 \\
50 & 0.02855 & 0.01142 & 0.04761 & 0.43790 & 114 & 18346.31 \\
\hline
\end{tabular}

Table 4

Sensitivity analysis of setup cost $\mathrm{k}_{\mathrm{s}}$ on optimal values of $\mathrm{T}_{1}, \mathrm{~T}_{2}, \mathrm{~T}_{3}, \mathrm{~T}, \mathrm{Q}$ and TC.

\begin{tabular}{ccccccc}
\hline $\mathrm{k}_{\mathrm{s}}$ & $\mathrm{T}_{1}$ & $\mathrm{~T}_{2}$ & $\mathrm{~T}_{3}$ & $\mathrm{~T}$ & $\mathrm{Q}$ & $\mathrm{TC}$ \\
\hline 150 & 0.02087 & 0.00835 & 0.03293 & 0.31072 & 83 & 25394.76 \\
140 & 0.02011 & 0.00805 & 0.03187 & 0.30015 & 80 & 24576.24 \\
130 & 0.01933 & 0.00773 & 0.03077 & 0.28919 & 77 & 23727.83 \\
120 & 0.01852 & 0.00741 & 0.02963 & 0.27780 & 74 & 22845.97 \\
110 & 0.01767 & 0.00707 & 0.02844 & 0.26592 & 71 & 21926.38 \\
100 & 0.01679 & 0.00672 & 0.02719 & 0.25349 & 67 & 20963.75 \\
\hline
\end{tabular}

The following results are made from Fig. 3 to 6 . The optimal production period is sensitive to changes in $k, h_{s}$ and moderately sensitive with other parameters. The optimal total cost per unit time tends to increase when the value of the parameters increase. The rework production run time increases when $h_{s}$ decreases, decreases when $k_{r}$ and $s_{c}$ increase while $k_{s}$ decreases. The non-production run time $\mathrm{T}_{3}$ is increasing when holding cost, scrap cost and rework setup cost increased. Hence the manufacturer has to keep the inventory having small quantities. The economic quantity is highly sensitive to $k_{r}, k_{s}$ 
and $h_{s}$ and moderately sensitive with $s_{c}$. The order quantity increases when $h_{s}$ decrease and decrease when $k_{r}$ and $k_{s}$ increase while $k_{s}$ decrease. The total inventory cost per unit time increases when $k_{s}$ and $s_{c}$ increase and decreases when $h_{s}$ and $k_{s}$ decrease.

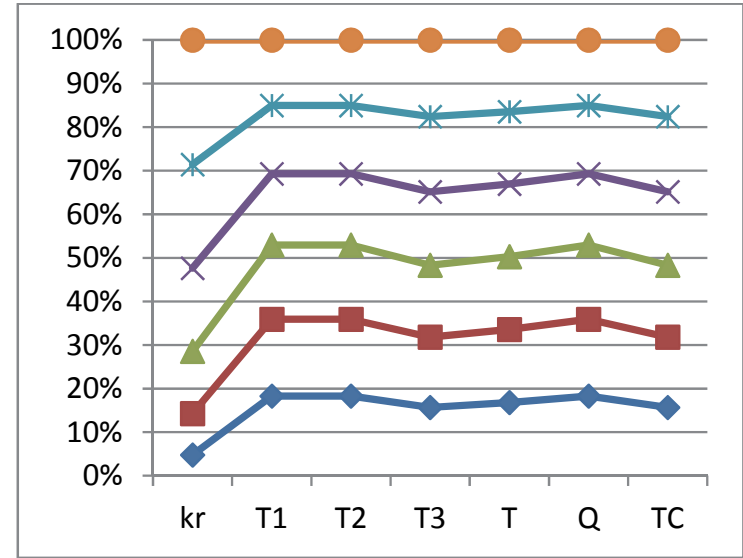

Fig. 3. Changes in optimal values in percentage with respect to $k_{r}$

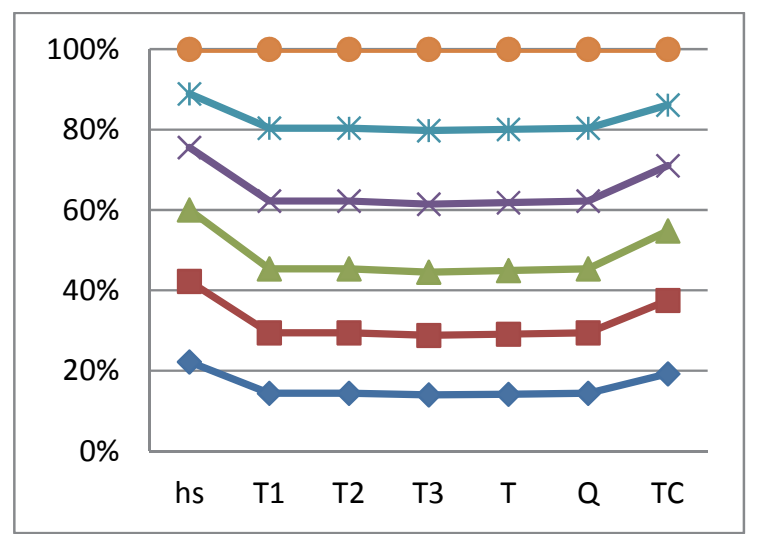

Fig. 5. Changes in optimal values in percentage with respect to $h_{s}$

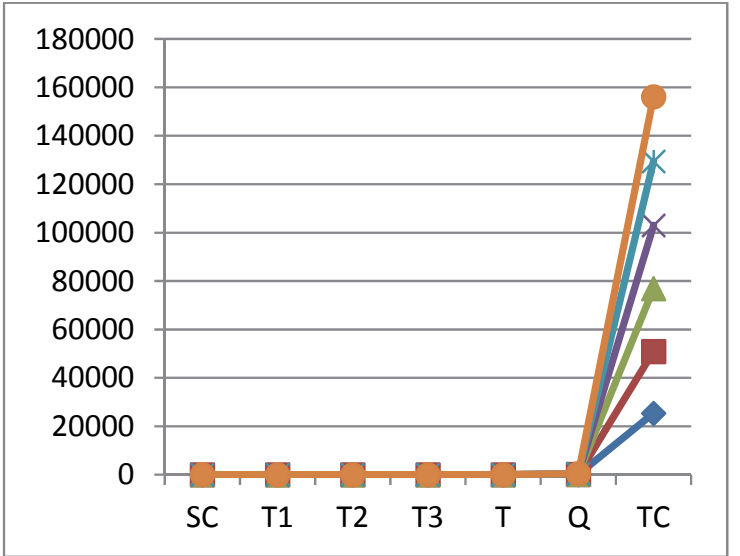

Fig. 4. Total cost with respect to optimal values and $s_{c}$

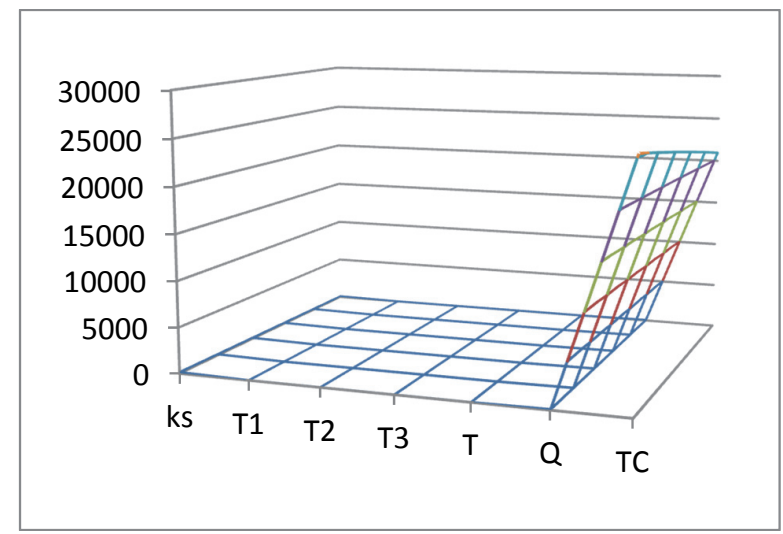

Fig. 6. Total cost with respect to optimal values and $\mathrm{k}_{\mathrm{s}}$

\section{Conclusion}

In this model, we have studied the inventory production system for defective and deteriorating items in which the production process contains multi-production setups and in each production setup, rework production setup is developed. Production setup cost consists of raw material cost, labor cost and environmental pollution cost. Since the production process is imperfect, the defective items are produced. The defective items are reworked as original quality items and the items are passed to customers. This EPQ inventory model investigates optimal replenishment quantity, optimal number of replenishment, optimal production run time and optimal finite planing horizon time. An algorithm is presented for deriving the optimal values. The sensitivity analysis shows that the production cost, setup cost and holding cost of serviceable items are much affected in the proposed model. This paper presents an inventory model of direct application to the venture that consider the fact that the storage item is deteriorated during storage periods and defective items are produced during production period.

\section{Acknowledgement}

The authors would like to thank Editor Babak Farhang and anonymous referees for their valuable and constructive comments and suggestions. The research work has been supported by University Grants Commission (UGC-SAP), New Delhi, India. 


\section{References}

Barketau, M. S., Cheng, T. E., \& Kovalyov, M. Y. (2008). Batch scheduling of deteriorating reworkables. European Journal of Operational Research, 189(3), 1317-1326.

Drury, C. G. (1978). Integrating human factors models into statistical quality control. Human Factors: The Journal of the Human Factors and Ergonomics Society, 20(5), 561-572.

Drury, C. G., \& Prabhu, P. V., (1994). Human factors in test and inspection. In G. Salvendy \& W. Karwowski (Eds.), Design of work and development of personnel in advanced manufacturing (pp. 355-401). New York: John Wiley \& Sons Inc.

Hsu, L. F., \& Hsu, J. T. (2016). Economic production quantity (EPQ) models under an imperfect production process with shortages backordered. International Journal of Systems Science, 47(4), 852-867.

Jaggi, C. K., Tiwari, S., \& Shafi, A. (2015). Effect of deterioration on two-warehouse inventory model with imperfect quality. Computers \& Industrial Engineering, 88, 378-385.

Jaggi, C., Khanna, A., \& Nidhi, N. (2016a). Effects of inflation and time value of money on an inventory system with deteriorating items and partially backlogged shortages. International Journal of Industrial Engineering Computations, 7(2), 267-282.

Jaggi, C., Tiwari, S., \& Goel, S. (2016b). Replenishment policy for non-instantaneous deteriorating items in a two storage facilities under inflationary conditions. International Journal of Industrial Engineering Computations, 7(3), 489-506.

Khouja, M. (2000). The economic lot and delivery scheduling problem: common cycle, rework, and variable production rate. IIE Transactions, 32(8), 715-725.

Kaliraman, N.K., Raj, R., Chandra, S., \& Chaudhry, H. (2015). An EPQ inventory model for deteriorating items with Weibull deterioration under stock dependent demand. International Journal of Scientific \& Technology Research, 4(1), 232-236.

Khanna, A., Kishore, A., \& Jaggi, C. (2017). Strategic production modeling for defective items with imperfect inspection process, rework, and sales return under two-level trade credit. International Journal of Industrial Engineering Computations, 8(1), 85-118.

Kumar, M., Chauhan, A., \& Kumar, P. (2011). Economic production lot size model with stochastic demand and shortage partial backlogging rate under imperfect quality items. International Journal of Advanced Science and Technology (IJAST), 31(1), 1-22.

Kumar, S., \& Rajput, U. S. (2016). A Probabilistic Inventory Model for Deteriorating Items with Ramp Type Demand Rate under Inflation. American Journal of Operational Research, 6(1), 16-31.

Mishra, V. K., Singh, L. S., \& Kumar, R. (2013). An inventory model for deteriorating items with timedependent demand and time-varying holding cost under partial backlogging. Journal of Industrial Engineering International, 9(1), 1-5.

Mukhopadhyay, A., \& Goswami, A. (2013). Economic Production Quantity (EPQ) model for three type imperfect items with rework and learning in setup. An International Journal of Optimization and Control: Theories \& Applications (IJOCTA), 4(1), 57-65.

Pal, S., Mahapatra, G. S., \& Samanta, G. P. (2014). An EPQ model of ramp type demand with Weibull deterioration under inflation and finite horizon in crisp and fuzzy environment. International Journal of Production Economics, 156, 159-166.

Pal, S., Mahapatra, G. S., \& Samanta, G. P. (2015). A production inventory model for deteriorating item with ramp type demand allowing inflation and shortages under fuzziness. Economic Modelling, 46, 334-345.

Rastogi, M., Singh, S., Kushwah, P., \& Tayal, S. (2017). Two warehouse inventory policy with price dependent demand and deterioration under partial backlogging. Decision Science Letters, 6(1), 11 22.

Rezaei, J., \& Salimi, N. (2012). Economic order quantity and purchasing price for items with imperfect quality when inspection shifts from buyer to supplier. International Journal of Production Economics, 137(1), 11-18. 
Sangal, I., Agarwal, A., \& Rani, S. (2016). A fuzzy environment inventory model with partial backlogging under learning effect. International Journal of Computer Applications, 137, 25-32.

Sarkar, B., Cárdenas-Barrón, L. E., Sarkar, M., \& Singgih, M. L. (2014). An economic production quantity model with random defective rate, rework process and backorders for a single stage production system. Journal of Manufacturing Systems, 33(3), 423-435.

Schrady, D. A. (1967). A deterministic inventory model for reparable items. Naval Research Logistics Quarterly, 14(3), 391-398.

Shukla, H., Tripathi, R., \& Sang, N. (2016). Economic production quantity model for defective items under deterioration. Uncertain Supply Chain Management, 4(3), 221-232.

Singh, S., Jain, S., \& Pareek, S. (2014). An economic production model for time dependent demand with rework and multiple production setups. International Journal of Industrial Engineering Computations, 5(2), 305-314.

Singh, S.R., Agarwal, A., \& Rani. S. (2015). Mathematical production inventory model for deteriorating items with time dependent demand rate under the effect of inflation and shortages. International Journal of Computer \& Mathematical Sciences, 4, 138-148.

Tai, A. H. (2013). Economic production quantity models for deteriorating/imperfect products and service with rework. Computers \& Industrial Engineering, 66(4), 879-88.

Widyadana, G. A., \& Wee, H. M. (2012). An economic production quantity model for deteriorating items with multiple production setups and rework. International Journal of Production Economics, $138(1), 62-67$.

Yassine, A., Maddah, B.,\& Salameh, M., (2012). Disaggregation and consolidation of imperfect quality shipments in an extended EPQ model. International Journal of Production Economics, 135(1), 345-52.

Yoo, S. H., Kim, D., \& Park, M. S. (2009). Economic production quantity model with imperfectquality items, two-way imperfect inspection and sales return. International Journal of Production Economics, 121(1), 255-265.

Zhou, Y., Chen, C., Li, C., \& Zhong, Y. (2016). A synergic economic order quantity model with trade credit, shortages, imperfect quality and inspection errors. Applied Mathematical Modelling, 40(2), 1012-1028.

\section{Appendix}

\section{Proof of Theorem 1.}

Differentiating $T C\left(T_{1}, T\right)=A T+B T_{1}+\frac{C}{T}+D \frac{T_{1}}{T}+E \frac{T_{1}^{2}}{T}+F$ with respect to $T_{1}$ and $T$ we get

$\frac{\partial T C}{\partial T_{1}}=B+\frac{D}{T}+\frac{2 E T_{1}}{T}$

$\frac{\partial T C}{\partial T}=A-\frac{C}{T^{2}}-\frac{D T_{1}}{T^{2}}-E \frac{T_{1}^{2}}{T^{2}}$

Solving $\frac{\partial T C}{\partial T_{1}}=0$ and $\frac{\partial T C}{\partial T}=0$ simultaneously, one can get the optimal pair $\left(T_{1}, T\right)$ which is given by

$$
\left(T_{1}^{*}, T^{*}\right)=\left(\frac{-1}{2 E}\left(B \sqrt{\frac{4 C E-D^{2}}{4 A E-B^{2}}}+D\right), \sqrt{\frac{4 C E-D^{2}}{4 A E-B^{2}}}\right)
$$

Since we must have $T_{1}^{*}>0$ and $T^{*}>0$, we get

$$
4 C E>D^{2}, 4 A E>D^{2}, B<0 \text { and } B \sqrt{4 C E-D^{2}}>D \sqrt{4 A E-D^{2}} \text {. }
$$


The Hessian matrix is given by

$H=\left(\begin{array}{cc}\frac{2 E}{T} & -\left(\frac{D}{T^{2}}+\frac{2 E T_{1}}{T^{2}}\right) \\ -\left(\frac{D}{T^{2}}+\frac{2 E T_{1}}{T^{2}}\right) & \frac{C}{T^{3}}+\frac{D T_{1}}{T^{3}}+\frac{E T_{1}^{2}}{T^{3}}\end{array}\right)$

Since $\operatorname{det}\left(H_{1}\right)=\frac{2 E}{T}>0$ and $\operatorname{det}\left(H_{2}\right)=\frac{1}{T^{4}}\left(2 E C-2 D E T_{1}-2 E^{2} T_{1}^{2}-D^{2}\right)>0, H$ is positive definite and hence the objective function $T C\left(T_{1}, T\right)$ is strictly convex.

\section{Derivation of second term of TC in Eq. (15).}

$\frac{h_{s}}{T / m}\left\{m \int_{0}^{T_{1}} \mathrm{I}_{1}\left(\mathrm{t}_{1}\right) d t_{1}+m \int_{0}^{T_{2}} \mathrm{I}_{2}\left(\mathrm{t}_{2}\right) d t_{2}+m \int_{0}^{T_{3}} \mathrm{I}_{3}\left(\mathrm{t}_{3}\right) d t_{3}\right\}+\frac{h_{r}}{T / m}\left\{\frac{m\left(T_{1}+T_{2}\right) p_{r} T_{2}}{2}\right\}$

Using the equations (2), (4) and (6) in the above term, one can obtain the following:

$$
\begin{aligned}
& =\frac{m^{2} h_{S}}{T}\left[\begin{array}{c}
\int_{0}^{T_{1}} \frac{(\alpha p-d)}{\gamma \theta}\left[1-e^{-\gamma \theta t_{1}}\right] d t_{1} \\
\int_{0}^{T_{2}}\left[\left(I_{s}-\frac{\left(\alpha_{r} p_{r}-d\right)}{\gamma \theta}\right) e^{-\gamma \theta t_{2}}+\frac{\left(\alpha_{r} p_{r}-d\right)}{\gamma \theta}\right] d t_{2} \\
+\int_{0}^{T_{3}} \frac{d}{\gamma \theta}\left[e^{\gamma \theta\left(T_{3}-t_{3}\right)}-1\right] d t_{3}
\end{array}\right]+\frac{m^{2} h_{r}}{T}\left\{\frac{\left(T_{1}+T_{2}\right) p_{r} T_{2}}{2}\right\} \\
& =\frac{m^{2} h_{s}}{T}\left[\begin{array}{l}
\frac{(\alpha p-d)}{\gamma \theta} \int_{0}^{T_{1}}\left[1-e^{-\gamma \theta t_{1}}\right] d t_{1} \\
+\left(I_{s}-\frac{\left(\alpha_{r} p_{r}-d\right)}{\gamma \theta}\right) \int_{0}^{T_{2}} e^{-\gamma \theta t_{2}} d t_{2}+\frac{\left(\alpha_{r} p_{r}-d\right)}{\gamma \theta} \int_{0}^{T_{2}} d t_{2} \\
+\frac{d}{\gamma \theta} \int_{0}^{T_{3}}\left[e^{\gamma \theta\left(T_{3}-t_{3}\right)}-1\right] d t_{3}
\end{array}\right]+\frac{m^{2} h_{r}}{T}\left\{\frac{\left(T_{1}+T_{2}\right) p_{r} T_{2}}{2}\right\} \\
& =\frac{m^{2} h_{s}}{T}\left[\begin{array}{c}
\frac{(\alpha p-d)}{\gamma \theta}\left[t_{1}+\frac{e^{-\gamma \theta t_{1}}}{\gamma \theta}\right]_{0}^{T_{1}} \\
+\left(I_{S}-\frac{\left(\alpha_{r} p_{r}-d\right)}{\gamma \theta}\right)\left[\frac{e^{-\gamma \theta t_{2}}}{-\gamma \theta}\right]_{0}^{T_{2}}+\frac{\left(\alpha_{r} p_{r}-d\right)}{\gamma \theta} T_{2} \\
-\frac{d}{\gamma \theta}\left[\frac{e^{\gamma \theta T_{3}} e^{-\gamma \theta t_{3}}}{\gamma \theta}+t_{3}\right]_{0}^{T_{3}}
\end{array}\right]+\frac{m^{2} h_{r}}{T}\left\{\frac{\left(T_{1}+T_{2}\right) p_{r} T_{2}}{2}\right\} \\
& =\frac{m^{2} h_{S}}{T}\left[\begin{array}{c}
\frac{(\alpha p-d)}{\gamma \theta}\left[T_{1}+\frac{e^{-\gamma \theta T_{1}}}{\gamma \theta}-\frac{1}{\gamma \theta}\right] \\
+\left(I_{S}-\frac{\left(\alpha_{r} p_{r}-d\right)}{\gamma \theta}\right)\left[\frac{e^{-\gamma \theta T_{2}}}{-\gamma \theta}+\frac{1}{\gamma \theta}\right]+\frac{\left(\alpha_{r} p_{r}-d\right)}{\gamma \theta} T_{2} \\
-\frac{d}{\gamma \theta}\left[\frac{1}{\gamma \theta}+T_{3}-\frac{e^{\gamma \theta T_{3}}}{\gamma \theta}\right]
\end{array}\right]+\frac{m^{2} h_{r}}{T}\left\{\frac{\left(T_{1}+T_{2}\right) p_{r} T_{2}}{2}\right\}
\end{aligned}
$$

We use the Taylor series approximation under the assumptions that $\gamma \theta T_{1}, \gamma \theta T_{2}$ and $\gamma \theta T_{3}$ are small. We espouse that $e^{x} \approx 1+x+\frac{x^{2}}{2}$. (see Tai (2013)) 


$$
\begin{gathered}
=\frac{m^{2} h_{s}}{T}\left[\begin{array}{c}
\frac{(\alpha p-d)}{\gamma \theta}\left[T_{1}+\frac{\left(1-\gamma \theta T_{1}+\frac{\left(\gamma \theta T_{1}\right)^{2}}{2}\right)}{\gamma \theta}-\frac{1}{\gamma \theta}\right] \\
+\left(I_{s}-\frac{\left(\alpha_{r} p_{r}-d\right)}{\gamma \theta}\right)\left[\frac{\left(1-\gamma \theta T_{2}+\frac{\left(\gamma \theta T_{2}\right)^{2}}{2}\right)}{-\gamma \theta}+\frac{1}{\gamma \theta}\right]+\frac{\left(\alpha_{r} p_{r}-d\right)}{\gamma \theta} T_{2} \\
-\frac{d}{\gamma \theta}\left[\frac{1}{\gamma \theta}+T_{3}-\frac{\left(1+\gamma \theta T_{3}+\frac{\left(\gamma \theta T_{3}\right)^{2}}{2}\right)}{\gamma \theta}\right]+\frac{m^{2} h_{r}}{T}\left\{\frac{\left(T_{1}+T_{2}\right) p_{r} T_{2}}{2}\right\}
\end{array}\right] \\
=\frac{m^{2} h_{s}}{T}\left[\frac{(\alpha p-d) T_{1}^{2}}{2}+\left(I_{S}-\frac{\left(\alpha_{r} p_{r}-d\right)}{\gamma \theta}\right)\left[T_{2}-\frac{\gamma \theta T_{2}^{2}}{2}\right]+\frac{\left(\alpha_{r} p_{r}-d\right)}{\gamma \theta} T_{2}+\frac{d T_{3}^{2}}{2}\right]+\frac{m^{2} h_{r}}{T}\left\{\frac{\left(T_{1}+T_{2}\right) p_{r} T_{2}}{2}\right\}
\end{gathered}
$$

Using $e^{x} \approx 1+x+\frac{x^{2}}{2}$ in Eq. (7), we can get $I_{S}=(\alpha p-d)\left(T_{1}-\frac{\gamma \theta T_{1}^{2}}{2}\right)$

$$
\begin{aligned}
& =\frac{m^{2} h_{s}}{T}\left[\frac{(\alpha p-d) T_{1}^{2}}{2}+\left((\alpha p-d)\left(T_{1}-\frac{\gamma \theta T_{1}^{2}}{2}\right)-\frac{\left(\alpha_{r} p_{r}-d\right)}{\gamma \theta}\right)\left[T_{2}-\frac{\gamma \theta T_{2}^{2}}{2}\right]+\frac{\left(\alpha_{r} p_{r}-d\right)}{\gamma \theta} T_{2}+\frac{d T_{3}^{2}}{2}\right]+\frac{m^{2} h_{r}}{T}\left\{\frac{\left(T_{1}+T_{2}\right) p_{r} T_{2}}{2}\right\} \\
& =\frac{m^{2} h_{s}}{T}\left[\frac{(\alpha p-d) T_{1}^{2}}{2}+(\alpha p-d)\left(T_{1}-\frac{\gamma \theta T_{1}^{2}}{2}\right)\left(T_{2}-\frac{\gamma \theta T_{2}^{2}}{2}\right)+\frac{\left(\alpha_{r} p_{r}-d\right) T_{2}^{2}}{2}+\frac{d T_{3}^{2}}{2}\right]+\frac{m^{2} h_{r}}{T}\left\{\frac{\left(T_{1}+T_{2}\right) p_{r} T_{2}}{2}\right\}
\end{aligned}
$$

Since $\left(1-\frac{\gamma \theta T_{1}}{2}\right)\left(1-\frac{\gamma \theta T_{2}}{2}\right) \approx 1$, the above term can be simplified as:

$$
=\frac{m^{2} h_{s}}{T}\left[\frac{(\alpha p-d) T_{1}^{2}}{2}+(\alpha p-d) T_{1} T_{2}+\frac{\left(\alpha_{r} p_{r}-d\right) T_{2}^{2}}{2}+\frac{d T_{3}^{2}}{2}\right]+\frac{m^{2} h_{r}}{T}\left\{\frac{\left(T_{1}+T_{2}\right) p_{r} T_{2}}{2}\right\}
$$

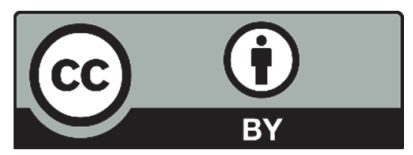

(C) 2016 by the authors; licensee Growing Science, Canada. This is an open access article distributed under the terms and conditions of the Creative Commons Attribution (CC-BY) license (http://creativecommons.org/licenses/by/4.0/). 